\title{
Myoglobin A79G polymorphism association with exercise-induced skeletal muscle damage
}

\author{
T. Cui and M.S. Jiang \\ Ji'nan, Shandong, China \\ Corresponding author: T. Cui \\ E-mail: cuitaoo@126.com \\ Genet. Mol. Res. 15 (2): gmr.15027506 \\ Received August 24, 2015 \\ Accepted December 10, 2015 \\ Published May 23, 2016 \\ DOI http://dx.doi.org/10.4238/gmr.15027506
}

College of Physical Education, Shandong University of Finance and Economics,

\begin{abstract}
We assessed the role of A79G, a polymorphism of the myoglobin gene $(M B)$, in susceptibility to exercise-induced skeletal muscle damage. Between January 2012 and December 2014, a total of 166 cases with exercise-induced skeletal muscle damage and 166 controls were recruited into our study. Genotyping of $M B$ A79G was carried out using polymerase chain reaction coupled with restriction fragment length polymorphism. Using unconditional logistic regression analysis, we found that the GG genotype of $M B$ A79G was associated with higher risk of exercise-induced muscle damage compared with the wild-type genotype, and the OR (95\%CI) was 2.91 (1.20-7.59). Compared with the AA genotype, the $\mathrm{AG}+\mathrm{GG}$ genotype was associated with a significantly increased risk of exercise-induced muscle damage for those with blood lactic acid $\geq 1.80 \mathrm{mM}(\mathrm{OR}=2.05 ; 95 \% \mathrm{CI}=1.09$ 3.88). In conclusion, we found that the A79G polymorphism of the $M B$ gene plays an important role in influencing the development of exercise-induced skeletal muscle damage.
\end{abstract}

Key words: Myoglobin; Exercise-induced skeletal muscle damage; Polymorphism 


\section{INTRODUCTION}

Exercise-induced muscle damage has been identified as one of the main causes of the progressive decrease in running and muscular performance experienced during marathon races. Eccentric muscle contraction, in which muscle fibers stretch during force generation, creates high tension in muscle fibers and is more likely to result in contraction-induced muscle damage. Several studies have reported that continuous intensive training, especially involving eccentric muscle contraction, could cause delayed skeletal muscle ache, muscle rigidity, power loss, and increased levels of creatine kinase $(\mathrm{CK})$ and myoglobin $(\mathrm{Mb})$ in the muscle, thereby inducing exertional rhabdomyolysis (Chen and Hsieh, 2001; Falla et al., 2013). Exertional rhabdomyolysis is a condition in which unaccustomed, intense exercise causes a breakdown of muscle tissue, resulting in the leakage of myofibrillar-associated compounds, such as CK and $\mathrm{Mb}$, into the circulation (Pearcey et al., 2013).

$\mathrm{Mb}$ is used to store oxygen in the muscle cells, and acts by combining with it (Schlater et al., 2014). When people engage in rigorous exercise, the skeletal muscle undergoes mild injury due to oxygen deficiency. However, the extent of the resulting skeletal muscle damage depends on the function of the genetic variants of the $M B$ gene, and varies from individual to individual. Previous studies have reported that CK genetic polymorphisms are associated with skeletal muscle strength and change in strength with resistance training, as well as exerciseinduced skeletal muscle damage (Heled et al., 2007; Kenney et al., 2012). CK is commonly used as a surrogate for $\mathrm{Mb}$, and the $\mathrm{A} 79 \mathrm{G}$ polymorphism of the $M B$ gene may play an important role in the development of exercise-induced skeletal muscle damage. In this study, we aimed to assess the role of A79G in the susceptibility of exercise-induced skeletal muscle damage.

\section{MATERIAL AND METHODS}

\section{Subjects}

Between January 2012 and December 2014, a total of 166 cases with exerciseinduced skeletal muscle damage were recruited from the College of Physical Education at the Shandong University of Finance and Economics. Subjects who had myopathy, myositis, diabetes, or hyperthyroidism were excluded from our study.

A total of 166 subjects without exercise-induced skeletal muscle damage were also recruited from the College of Physical Education at the Shandong University of Finance and Economics, and these subjects were considered controls. Each control subject was matched by sex and age ( \pm 5 years) with each case subject.

Fasting venous blood $(20 \mu \mathrm{L})$ was taken from each subject and the level of blood lactic acid was determined using a portable LT-1710 blood lactic acid meter (ARKRAY Factory, Inc., Kyoto, Japan). Each participant's height and weight was recorded. Written informed consent was obtained from all subjects included in the study. The protocol of our study was approved by the ethics committee of the College of Physical Education at the Shandong University of Finance and Economics.

\section{Genotyping}

Peripheral blood samples $(2 \mathrm{~mL})$ were drawn from the subjects with exercise-induced 
skeletal muscle damage and from the control subjects, and the blood samples were stored at $-80^{\circ} \mathrm{C}$ until required. Genotyping of the $M B$ A79G polymorphism was carried out using polymerase chain reaction (PCR) coupled with restriction fragment length polymorphism (RFLP). The forward and reverse primers for $M B$ A79G were 5'-TTGTCTGGGTGCATTTCAAG-3' and 5'-GCCCTGGCACAGCCACCATC-3'. The PCR reaction was performed in a $25-\mu \mathrm{L}$ reaction solution comprising $25 \mathrm{mM} \mathrm{MgCl}$, each primer with $2 \mathrm{mM}$ deoxynucleotide triphosphates, $1 \mathrm{mM} \mathrm{MgCl}, 1.25$ units Taq polymerase, and 5X PCR buffer. The restriction enzyme was EcoT22I. The products were 163 and 26 bp for the AA genotype, 189, 163, and 26 bp for the AG genotype, and $189 \mathrm{bp}$ for the GG genotype. The DNA was amplified at $95^{\circ} \mathrm{C}$ for $5 \mathrm{~min}$, followed by 35 cycles of denaturation at $94^{\circ} \mathrm{C}$ for $60 \mathrm{~s}$, annealing at $62^{\circ} \mathrm{C}$ for $60 \mathrm{~s}$, extension at $72^{\circ} \mathrm{C}$ for $2 \mathrm{~min}$, and a final extension at $72^{\circ} \mathrm{C}$ for $5 \mathrm{~min}$. For purposes of quality control, $5 \%$ of the patients were randomly selected to repeat the genotyping procedure conducted by different researchers. The reproducibility was $100 \%$.

\section{Statistical analysis}

Statistically significant differences in demographic and clinical characteristics between cases and controls were tested using the chi-squared method. Deviation from the Hardy-Weinberg equilibrium (HWE) of $M B$ A79G in the controls was evaluated using the Fisher's exact test. The chi-squared test was used to calculate the differences in genotype distribution between cases and controls. By using logistic regression models, the odds ratios (ORs) and 95\% confidence intervals (95\% CIs) were evaluated for the association between the $M B$ A79G polymorphism and the risk of exercise-induced skeletal muscle damage adjusted for confounding factors. A P value $<0.05$ was taken to indicate statistical significance. The Statistical Analyses System (SAS) package (version 8.01; SAS Institute, Cary, NC) was used for statistical analysis.

\section{RESULTS}

A total of 166 subjects with exercise-induced muscle damage were invited to participate in our study, and the demographic characteristics of cases with exercise-induced muscle damage and controls are shown in Table 1. The analysis showed that the blood lactic acid in cases with exercise-induced muscle damage was higher than in the controls (1.92 \pm $0.64 \mathrm{mM}$ vs $1.74 \pm 0.70 \mathrm{mM})$.

\section{Table 1. Demographic characteristics of included subjects.}

\begin{tabular}{l|c|c|c|c|c|c}
\hline Variables & Cases & $\%$ & Controls & $\%$ & $\chi^{2}$ test & P value \\
\hline Mean age, years & & $22.40 \pm 2.55$ & & $22.15 \pm 2.40$ & 0.92 & 0.18 \\
\hline$<25$ & 112 & 67.47 & 111 & 66.87 & & \\
\hline$\geq 25$ & 54 & 32.53 & 55 & 33.13 & 0.01 & 0.91 \\
\hline Gender & & & & & & \\
\hline Females & 70 & 42.17 & 70 & 42.17 & & \\
\hline Males & 96 & 57.83 & 96 & 57.83 & $<0.001$ & 1.00 \\
\hline Height $(\mathrm{m})$ & & $1.68 \pm 0.06$ & & $1.70 \pm 0.07$ & 2.80 & 0.003 \\
\hline Weight $(\mathrm{kg})$ & & $66.71 \pm 7.50$ & & $67.50 \pm 7.85$ & 0.94 & 0.17 \\
\hline BMI $\left(\mathrm{kg} / \mathrm{m}^{2}\right)$ & & $21.80 \pm 1.52$ & & $21.92 \pm 1.63$ & 0.69 & 0.24 \\
\hline Blood lactic acid $(\mathrm{mM})$ & & $1.92 \pm 0.64$ & & $1.74 \pm 0.70$ & 2.45 & 0.01 \\
\hline BMI & & & & &
\end{tabular}

$\mathrm{BMI}=$ body mass index. 
Using Fisher's exact test, we found that the genotype distribution of $M B$ A79G in the controls was in agreement with HWE (the P value for the deviation from HWE was 0.64 , i.e., not statistically significant). Using the chi-squared test, there was a significant difference between the genotype distribution of $M B$ A79G between cases and controls $\left(\chi^{2}\right.$ $=6.80 ; \mathrm{P}$ value $=0.03)$. Using unconditional logistic regression analysis, our study found that the GG genotype was associated with higher risk of exercise-induced muscle damage compared with the wild-type genotype in the codominant model, and the OR $(95 \% \mathrm{CI})$ was 2.91 (1.20-7.59) (Table 2). However, no significant difference was found between the $M B$ A79G polymorphism and development of exercise-induced muscle damage in the dominant and recessive models.

Table 2. Association between MB A79G polymorphism and development of exercise-induced muscle damage.

\begin{tabular}{l|c|c|c|c|c|c|c|c|c}
\hline Variables & Cases & $\%$ & Controls & $\%$ & $\chi^{2}$ test & P value & HWE & OR (95\%CI $)^{1}$ & P value \\
\hline Codominant & & & & & & & & & \\
\hline AA & 78 & 46.99 & 93 & 56.02 & & & & 1.0 (Ref.) & - \\
\hline AG & 66 & 39.76 & 64 & 38.55 & & & & $1.23(0.76-1.99)$ & 0.38 \\
\hline GG & 22 & 13.25 & 9 & 5.42 & 6.80 & 0.03 & 0.64 & $2.91(1.20-7.59)$ & 0.01 \\
\hline Dominant & & & & & & & & & \\
\hline AA & 86 & 51.81 & 93 & 56.02 & & & & 1.0 (Ref.) & - \\
\hline AG+GG & 88 & 53.01 & 73 & 43.98 & 1.48 & 0.22 & & $1.30(0.83-2.04)$ & 0.22 \\
\hline Recessive & & & & & & & & & \\
\hline AA+AG & 144 & 86.75 & 157 & 94.58 & & & & $1.0($ Ref. $)$ & - \\
\hline GG & 15 & 13.25 & 9 & 5.42 & 1.91 & 0.17 & & $1.82(0.72-4.86)$ & 0.17 \\
\hline
\end{tabular}

$\mathrm{HWE}=$ Hardy-Weinberg equilibrium ${ }^{1}$ Adjusted for age, gender, body mass index (BMI), and blood lactic acid .

Stratification analyses of age, sex, body mass index (BMI), and blood lactic acid of the $M B$ A79G polymorphism are shown in Table 3. Compared with the AA genotype, the $\mathrm{AG}+\mathrm{GG}$ genotype was associated with a significantly increased risk of exercise-induced muscle damage for those with blood lactic acid $\geq 1.80 \mathrm{mM}(\mathrm{OR}=2.05 ; 95 \% \mathrm{CI}=1.09-3.88)$. However, no association interaction was found between the $M B$ A79G polymorphism and age, sex, or BMI in the development of exercise-induced muscle damage.

Table 3. Interaction between $M B$ A79G polymorphism and characteristics of subjects in the development of exercise-induced muscle damage.

\begin{tabular}{|c|c|c|c|c|c|c|}
\hline \multirow[t]{3}{*}{ Variables } & \multicolumn{4}{|c|}{$M B$ A79G polymorphism } & \multirow[t]{2}{*}{ OR $(95 \% \mathrm{CI})$} & \multirow[t]{2}{*}{$P$ value } \\
\hline & \multicolumn{2}{|c|}{ Cases } & \multicolumn{2}{|c|}{ Controls } & & \\
\hline & AA & $\mathrm{AG}+\mathrm{GG}$ & $\mathrm{AA}$ & $\mathrm{AG}+\mathrm{GG}$ & \multicolumn{2}{|c|}{$\mathrm{AA} v s \mathrm{AG}+\mathrm{GG}$} \\
\hline \multicolumn{7}{|c|}{ Mean age, years } \\
\hline$<25$ & 58 & 54 & 62 & 49 & $1.18(0.67-2.06)$ & 0.54 \\
\hline$\geq 25$ & 28 & 26 & 31 & 24 & $1.20(0.53-2.73)$ & 0.64 \\
\hline \multicolumn{7}{|l|}{ Gender } \\
\hline Females & 38 & 32 & 40 & 30 & $1.12(0.55-2.31)$ & 0.73 \\
\hline Males & 48 & 48 & 53 & 43 & $1.23(0.67-2.26)$ & 0.47 \\
\hline \multicolumn{7}{|c|}{ BMI $\left(\mathrm{kg} / \mathrm{m}^{2}\right)$} \\
\hline$<21.5$ & 45 & 42 & 46 & 36 & $1.19(0.62-2.29)$ & 0.57 \\
\hline$\geq 21.5$ & 41 & 38 & 47 & 37 & $1.18(0.61-2.28)$ & 0.60 \\
\hline \multicolumn{7}{|c|}{ Blood lactic acid (mM) } \\
\hline$<1.80$ & 40 & 27 & 45 & 42 & $0.72(0.36-1.45)$ & 0.32 \\
\hline$\geq 1.80$ & 46 & 61 & 48 & 31 & $2.05(1.09-3.88)$ & 0.02 \\
\hline
\end{tabular}

$\mathrm{BMI}=$ body mass index. 


\section{DISCUSSION}

Polymorphisms have an effect on the regulation of gene expression, and they could contribute to the differences between individuals in the susceptibility to, and severity of, a disease. Previous studies have reported that molecular factors play an important role in the development of exercise-induced skeletal muscle damage. In this study, we investigated whether the $M B$ A79G polymorphism influences susceptibility to exercise-induced skeletal muscle damage. We found that the $M B$ A79G polymorphism was associated with the development of exercise-induced skeletal muscle damage in the codominant model.

$\mathrm{Mb}$ protein is the equivalent of hemoglobin in muscle cells, and its function is to transport oxygen in the blood through the membrane to the muscle cells (Sher et al., 2014). The oxygen is temporarily stored in the form of oxygenated $\mathrm{Mb}$, which meets the muscle's demand for oxygen during strenuous activity (Schlater et al., 2014). Therefore, Mb plays an important role in oxygen transportation. Previous studies have reported that the $M B$ A79G polymorphism in exon 2 of the $M B$ gene is associated with hypoxia resistance and training sensitivity in humans (Wu et al., 2005; Wu et al., 2009). Wu et al. (2009) reported that there may be an association between the 79A allele and high attitude tolerance in a Chinese population. Moreover, Wu et al. (2005) also conducted a study in a Chinese population and found that the $\mathrm{G}$ allele of the $M B$ A79G gene may contribute to individual differences in endurance training. Exercise-induced skeletal muscle damage is associated with oxygen deficiency in muscle cells, and is influenced by the $M B$ A79G polymorphism; thus, the genetic variation in $M B$ A79G may be associated with susceptibility to exercise-induced skeletal muscle damage.

Our study found that the GG genotype was associated with higher risk of exerciseinduced muscle damage compared with the wild-type genotype, which showed that the AA genotype had a protective role in exercise-induced muscle damage. To date, only one study conducted in a Chinese population has reported that the $M B$ A79G polymorphism contributes to the development of exercise-induced skeletal muscle damage, which is in agreement with our study (Peng et al., 2013). However, no study has investigated the mechanism underlying the association between the $M B$ A79G gene polymorphism and exercise-induced skeletal muscle damage. Therefore, further studies are required to confirm our findings.

In conclusion, our study found that the $M B \mathrm{~A} 79 \mathrm{G}$ polymorphism plays an important role in influencing the development of exercise-induced skeletal muscle damage. Large-scale case-control studies are urgently needed to determine more precisely the relationship between the $M B$ A79G polymorphism and the risk of exercise-induced skeletal muscle damage.

\section{Conflicts of interest}

The authors declare no conflict of interest.

\section{REFERENCES}

Chen TC and Hsieh SS (2001). Effects of a 7-day eccentric training period on muscle damage and inflammation. Med. Sci. Sports Exerc. 33: 1732-1738. http://dx.doi.org/10.1097/00005768-200110000-00018

Falla D, Lindstrøm R, Rechter L, Boudreau S, et al. (2013). Effectiveness of an 8-week exercise programme on pain and specificity of neck muscle activity in patients with chronic neck pain: a randomized controlled study. Eur. J. Pain 17: 1517-1528.

Heled Y, Bloom MS, Wu TJ, Stephens Q, et al. (2007). CK-MM and ACE genotypes and physiological prediction of the creatine kinase response to exercise. J. Appl. Physiol. (1985). 103: 504-510. 
Kenney K, Landau ME, Gonzalez RS, Hundertmark J, et al. (2012). Serum creatine kinase after exercise: drawing the line between physiological response and exertional rhabdomyolysis. Muscle Nerve 45: 356-362. http://dx.doi. org $/ 10.1002 /$ mus. 22317

Pearcey GE, Bradbury-Squires DJ, Power KE, Behm DG, et al. (2013). Exertional rhabdomyolysis in an acutely detrained athlete/exercise physiology professor. Clin. J. Sport Med. 23: 496-498. http://dx.doi.org/10.1097/ JSM.0b013e318291d39e

Peng P, Bo H, Zhang L, Diao Q, et al. (2013). Relationship between myoglobin gene polymorphism and exercise-induced muscle damage. Med. J. Chin. Peop. Armed Poli. Forc. 24: 97-100.

Schlater AE, De Miranda MA Jr, Frye MA, Trumble SJ, et al. (2014). Changing the paradigm for myoglobin: a novel link between lipids and myoglobin. J. Appl. Physiol. (1985). 117: 307-315.

Sher EA, Sholto AY, Shaklai M and Shaklai N (2014). Can gas replace protein function? CO abrogates the oxidative toxicity of myoglobin. PLoS One 9: e104075.http://dx.doi.org/10.1371/journal.pone.0104075

$\mathrm{Wu}$ J, Hu Y and Bao DP (2009). On allele frequencies of single nucleotide polymorphisms in the second exon of myoglobin gene in race of Han from Northern China. J. Cap. Inst. Phys. Educ. 21: 346-348.

Wu J, Hu Y, Liu G, Zhou DQ, et al. (2005). Association between myoglobin gene polymorphism and physical performance after endurance train. Clin. J. Sport Med. 24: 650-654. 